\title{
APLICAÇÃO DO TEAM BASED LEARNING NAS AULAS DE LABORATÓRIO DE MATERIAIS DE CONSTRUÇÃO CIVIL NUM CURSO DE ENGENHARIA
}

\author{
Heloísa Cristina Fernandes Cordon-heloisa.fernandes@maua.br \\ Instituto Mauá de Tecnologia, Engenharia Civil \\ Praça Mauá, 1 \\ CEP 09580-900 - São Caetano do Sul - SP \\ Octavio Mattasoglio Neto - omattasoglio@maua.br \\ Instituto Mauá de Tecnologia, Ciclo Básico \\ Praça Mauá, 1 \\ CEP 09580-900 - São Caetano do Sul - SP
}

Resumo: O ensino tradicional, com foco no professor, perdeu força nos últimos anos por conta da dificuldade de aprendizagem e crescente desmotivação dos alunos. Com isso, as metodologias de aprendizagem ativa ganharam destaque, uma vez que o aluno passa a ser o protagonista do processo e passa a controlar seu ritmo de aprendizado. Dentro deste cenário existem diversas ferramentas, entre elas: PBL (Problem/Project Based Learning), Aula Invertida, Aprendizagem por Pares, etc. $O$ objetivo deste trabalho é analisar o uso da ferramenta Team Based Learning (TBL), ou Aprendizagem por Equipes, nas aulas de laboratório da disciplina de Materiais de Construção Civil da Escola de Engenharia Mauá. A motivação foi o crescente desinteresse dos alunos ao longo dos últimos anos nas aulas tradicionais de laboratório. Para a atividade, os alunos se dividiram em equipes e cada uma ficou responsável por um dos experimentos de um bimestre letivo. $O$ material prévio para a preparação das equipes foi disponibilizado na plataforma moodlerooms e os alunos tinham o suporte do técnico para a preparação prévia do experimento que realizariam com o restante da turma no dia da sua apresentação. Ao final do processo, notou-se o engajamento das equipes e uma maior participação da turma durante as aulas, além da percepção positiva dos estudantes sobre o processo.

Palavras-chave: Aprendizagem ativa. Team Based Learning (TBL). Aprendizagem por equipe. Laboratório didático. Materiais de Construção Civil. 


\section{INTRODUÇÃO}

A aprendizagem ativa vem se tornando uma metodologia bastante corrente nos últimos anos. Nela, o aluno é protagonista e tem a oportunidade de controlar seu ritmo de aprendizagem. São diversas as ferramentas disponíveis para a implementação desta metodologia e entre elas destaca-se a Aprendizagem por Equipes (TBL - Team Based Learning), na qual os alunos trabalham em equipes para preparo e aplicação de conceitos a partir de conteúdos disponibilizados previamente. No caso da disciplina de Materiais de Construção Civil, cujas aulas de laboratório correspondem à metade da carga horária do curso, a implantação de metodologias ativas se torna adequada e atraente, uma vez que as classes são formadas por grupos reduzidos de até 25 alunos e o ambiente de laboratório favorece atividades "mão na massa".

O objetivo deste trabalho é apresentar a implantação e uso da estratégia TBL nas aulas de laboratório da disciplina Materiais da Construção Civil do curso de Engenharia do Instituto Mauá de Tecnologia, bem como apresentar dados e resultados de uma pesquisa que foi conduzida para avaliar a percepção dos estudantes sobre o uso dessa estratégia.

\section{REVISÃO BIBLIOGRÁFICA}

Larry Michaelsen e colegas, no final dos anos 1970, criaram o TBL para cursos de Administração com o objetivo de melhorar a aprendizagem e desenvolver habilidades de trabalho colaborativo de pequenas equipes de alunos (entre 5 e7), criando oportunidades aos estudantes para aplicarem conhecimentos conceituais através de uma sequência de atividades, como trabalho individual, trabalho em equipe e feedback imediato (BOLLELA et al., 2014; BURGESS; MCGREGOR; MELLIS, 2014; OLIVEIRA et al., 2018).

De acordo com Bollela et al. (2014), esta estratégia de aprendizagem é centrada no estudante, sob a coordenação de um professor especialista no assunto, que atua como facilitador da aprendizagem mediando estímulos e oportunidades para que todos os estudantes possam desenvolver habilidades e atitudes de representatividade, autonomia e comunicação.

O esquema ilustrado na Figura 1 apresenta as 4 etapas do TBL, sendo cada uma delas descrita a seguir (BOLLELA et al., 2014; OLIVEIRA et al., 2018):

1 Preparação pré-classe: os estudantes devem se preparar individualmente para o trabalho com leituras prévias ou outras atividades sugeridas pelo professor. Se esta etapa não for cumprida, o aluno não colabora adequadamente com a equipe, gerando dificuldades como ressentimento dos colegas e falta de coesão do grupo;

2 Garantia de preparo: pode ser realizada através da aplicação de testes em classe, que asseguram a aprendizagem, e debate sobre as questões aplicadas em sala, todos com feedback imediato;

3 Aplicação dos conceitos em classe, onde os estudantes em suas equipes devem aplicar os conhecimentos previamente estudados. Esta etapa é estruturada em função de 4 princípios básicos: problema significativo (os estudantes devem resolver problemas reais), mesmo problema (todas as equipes trabalham com o mesmo problema), escolha específica (as respostas devem ser curtas), e relatos simultâneos (todas as equipes apresentam as respostas simultaneamente);

Auto avaliação e avaliação entre os pares: os estudantes são avaliados pelo desempenho individual e pelo resultado do trabalho em equipe.

O uso de estratégias ativas de aprendizagem como é o caso do TBL, vai ao encontro das novas Diretrizes Curriculares Nacionais (DCN's) para os cursos de Engenharia (MEC, 2019), pelo seu potencial de desenvolvimento de competências transversais como liderança, 
capacidade de decisão, trabalho em equipe, análise crítica, dentre outras que moldam o profissional desejado nos dias de hoje (MESQUITA; LIMA; FLORES, 2013).

Figura 1 - Etapas do TBL.

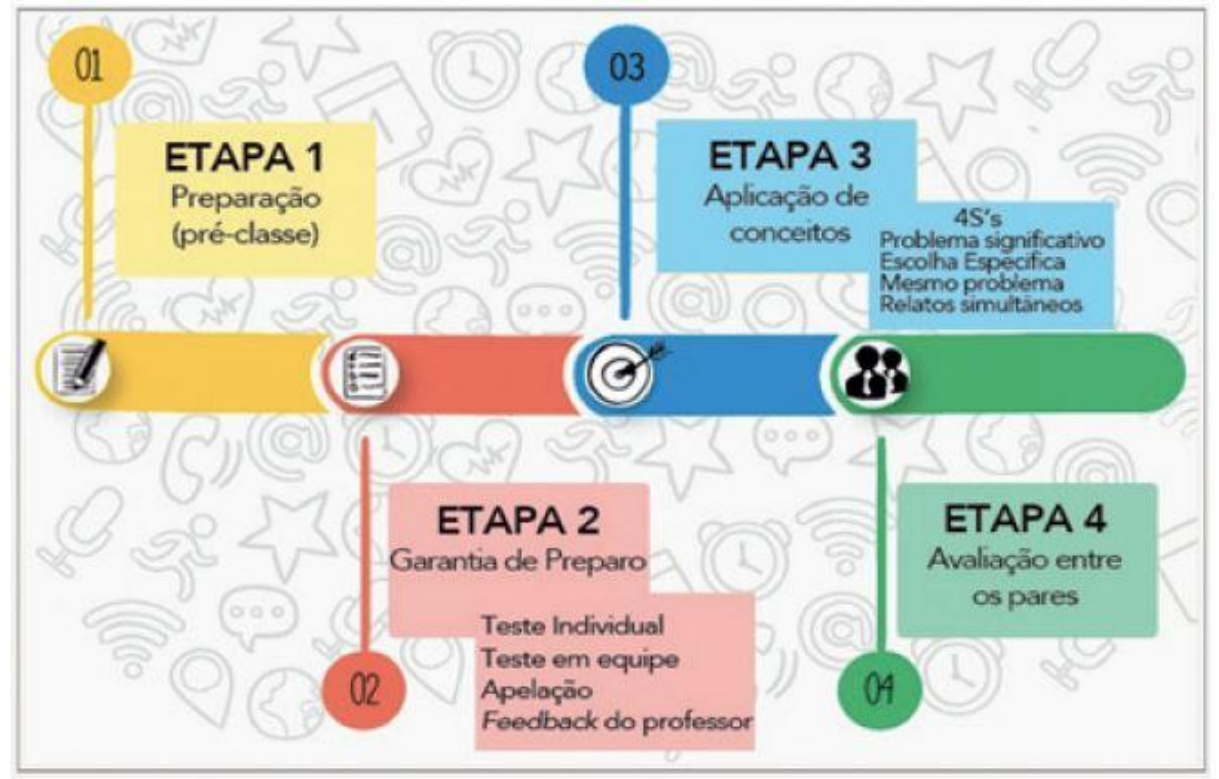

Fonte: Oliveira et al. (2018)

Como indicado, o objetivo deste trabalho é, além de apresentar a implementação da metodologia Team Based Learning (TBL) ou Aprendizagem por Equipes nas aulas de laboratório do $2^{\circ}$ bimestre de 2019 da disciplina de Materiais de Construção Civil da Escola de Engenharia Mauá, apresentar dados e resultados de uma pesquisa que foi conduzida para avaliar a percepção dos estudantes sobre o uso dessa estratégia. Detalha-se, em seguida, o levantamento dos dados e sua análise.

\section{MÉTODOS E TÉCNICAS DE PESQUISA}

\subsection{Implementação do Team Based Learning (TBL)}

Até o ano de 2018, a dinâmica utilizada nas aulas de laboratório da disciplina Materiais de Construção Civil constava de uma apresentação realizada pela professora no início da aula sobre os conceitos e os experimentos que seriam realizados no dia, cujo arquivo era disponibilizado para os alunos com antecedência na plataforma moodlerooms, juntamente com a apostila da aula em questão, que deveria ser levada impressa pelos alunos para preenchimento com os dados de ensaio. Após a apresentação, o técnico e a professora conduziam os experimentos, solicitando a participação dos alunos, que a cada ano se tornou mais escassa. A proposta do trabalho iniciada no ano de 2019 foi a de dividir a turma em equipes, sendo cada uma responsável por uma aula de laboratório do $2^{\circ}$ bimestre. Para cada equipe foi disponibilizado o material necessário para a preparação dos experimentos, no caso as normas brasileiras, bem como o modelo de apresentação e a apostila. O grupo era responsável por agendar uma data no laboratório para aprender os experimentos com o técnico e preparar a apresentação para os colegas. Na data da aula, o grupo responsável conduzia a apresentação e os experimentos, solicitando a participação dos colegas, sempre com o suporte da professora e do técnico. 
Após a realização da atividade, a avaliação foi realizada apenas pela professora, que atribuiu conceitos tanto individuais quanto para o grupo, como qualidade da apresentação, o domínio do conteúdo abordado, a preparação prévia dos experimentos e a condução da atividade. A nota resultante representava até $60 \%$ da nota total de trabalho daquele bimestre.

\subsection{Levantamento dos dados da pesquisa com os alunos}

Para a avaliação da percepção e do impacto causado pela atividade proposta nos alunos, foi elaborado um questionário na plataforma Google Forms, que se dividiu em 3 sessões, nas quais foi solicitado aos estudantes que respondessem:

- Sobre o material disponibilizado previamente para a preparação da aula pela sua equipe, indicando o seu grau de concordância;

- Sobre o treinamento prévio em laboratório, com o apoio do técnico de laboratório, para a preparação da aula pela sua equipe, indicando o seu grau de concordância;

- Sobre o trabalho desenvolvido na preparação das "AULAS DE LABORATÓRIO DE MATERIAIS DE CONSTRUÇÃO CIVIL" de maneira geral, indicando o seu grau de concordância.

As respostas foram categorizadas em uma escala de referência como a que segue: 5 . Concordo Totalmente; 4. Concordo; 3. Indiferente; 2. Discordo; 1. Discordo Totalmente.

\section{RESULTADOS E DISCUSSÕES}

Dos 51 alunos matriculados, 19 responderam ao questionário (37,2\%), sendo 57,9\% do sexo masculino e $42,1 \%$ do sexo feminino, com faixa etária de $31,6 \%$ entre 18 e 20 anos e $68,4 \%$ entre 21 e 23 anos. Quando questionados a respeito do conhecimento sobre ensaios laboratoriais de materiais de construção civil, 52,6\% afirmaram que já tinham ouvido falar, mas não sabiam direito o que era, 21,1\% afirmaram que nunca tinham ouvido falar, 15,8\% sabiam o que era, mas nunca tinham feito e $10,5 \%$ sabiam o que era e já tinham feito.

Os resultados percentuais da percepção dos estudantes sobre o material disponibilizado previamente para a preparação da aula estão apresentados da Figura 2. Observa-se que $53 \%$ dos estudantes responderam que não tiveram dificuldade em entender sozinhos o material disponibilizado previamente (Figura 2 b). No entanto, há a indicação de que utilizaram outros materiais além do disponibilizado pela professora (Figura 2 a).

$\mathrm{O}$ fato de considerarem o material adequado (Figura $2 \mathrm{c}$ ) e de o entenderem sem a necessidade de ajuda (Figura $2 \mathrm{~b}$ ), talvez indique que o material era incompleto, de modo que os estudantes recorreram a outros materiais (Figura 2 d) para complementar informações necessárias à preparação do experimento. 


\section{COBENGE (C) COBENGE 2020 da ABENGE}

\section{"Os desafios para formar hoje o engenheiro do amanhã"}

\section{$\mathrm{Ol} \mathrm{a} \mathrm{O} 3$ de dezembro}

Figura 2 - Resultados percentuais da percepção dos estudantes sobre o material disponibilizado previamente para a preparação da aula.

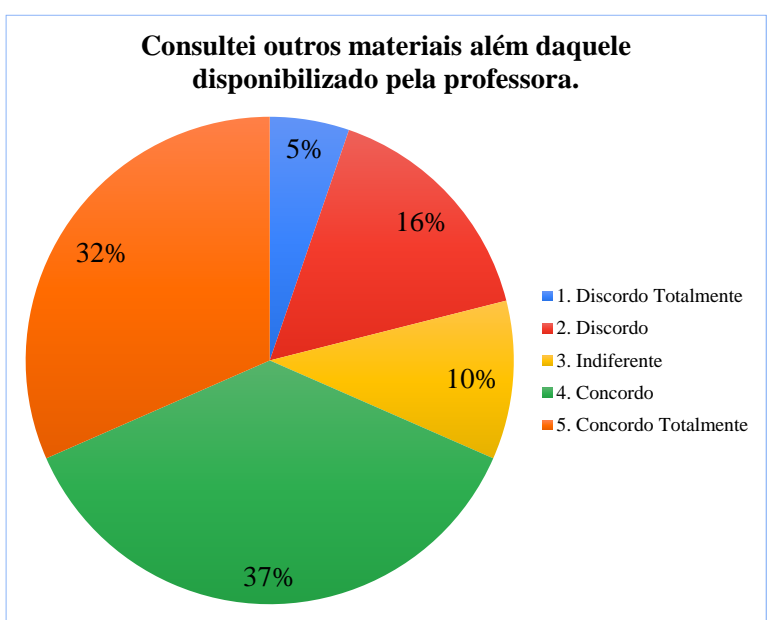

(a)

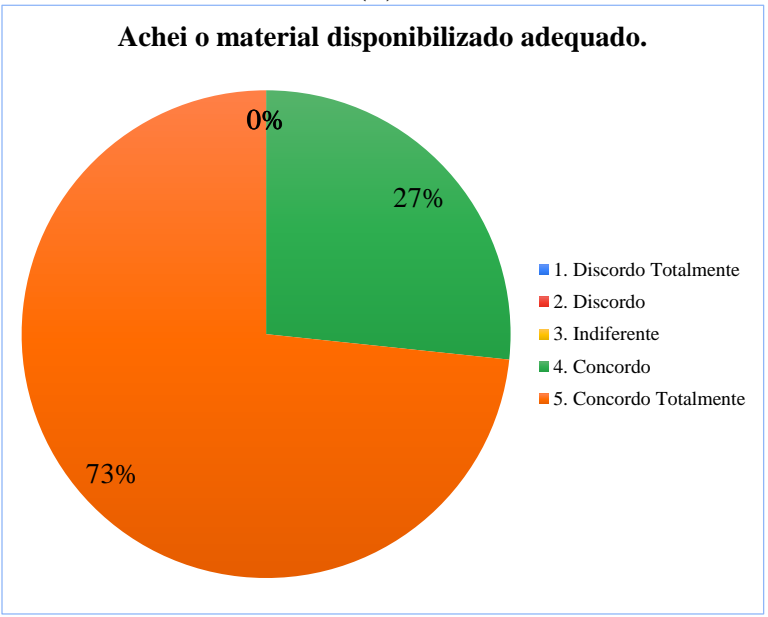

(c)

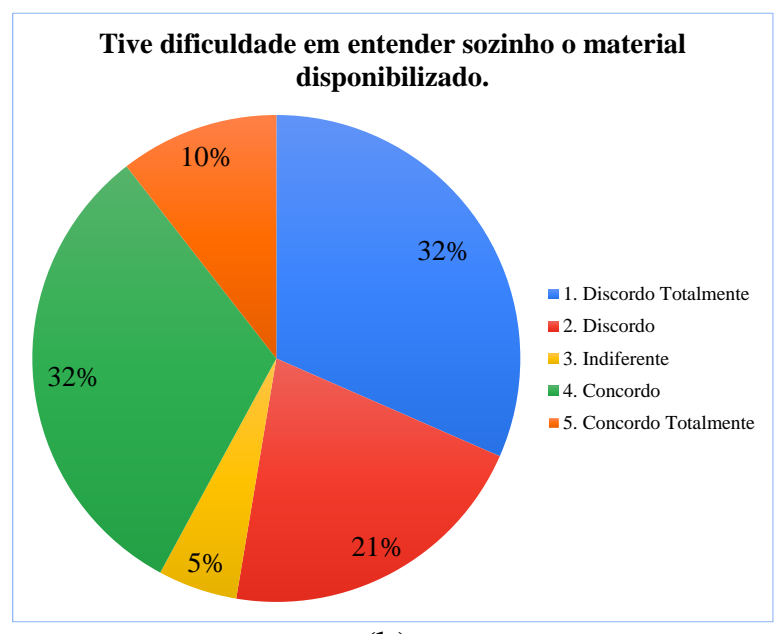

(b)

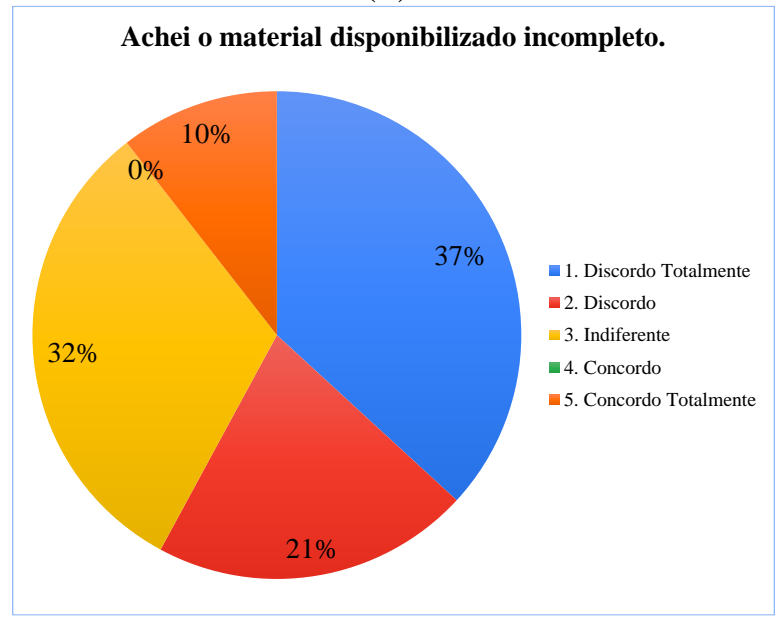

(d)

A Figura 3 apresenta os resultados percentuais da percepção dos alunos sobre o treinamento prévio em laboratório, com o apoio do técnico. Verifica-se que $100 \%$ dos alunos responderam que conseguiram aprender a realizar o experimento de acordo com as prescrições das normas (Figura 3 a) e se sentiram seguros para realizar o experimento durante a aula (Figura 3 b), apenas $11 \%$ afirmaram terem tido dificuldade para realizar o experimento (Figura $3 \mathrm{c}$ ). 


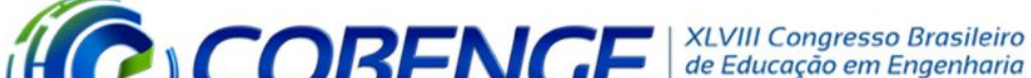 C. COBENCE 2020 de Educação em Engenharia da ABENGE}

\section{"Os desafios para formar hoje o engenheiro do amanhã"}

Figura 3 - Resultados percentuais da percepção dos estudantes sobre o material disponibilizado previamente para a preparação da aula.

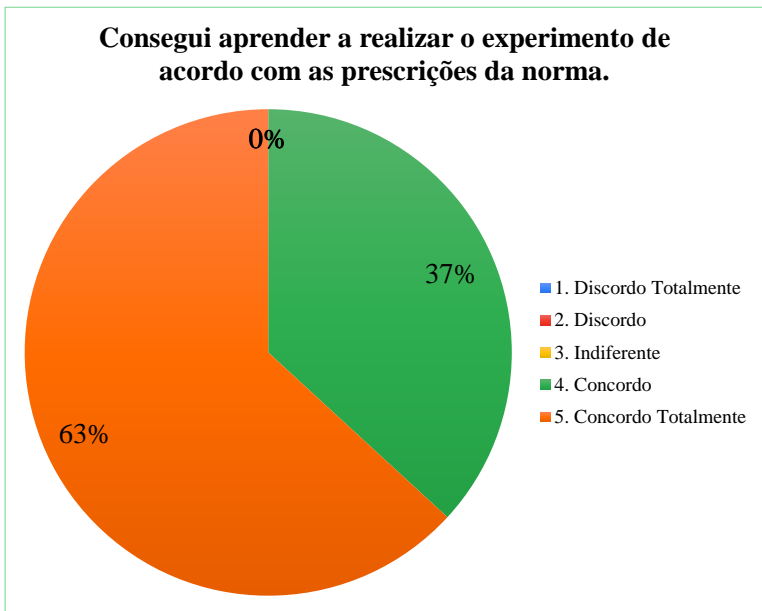

(a)

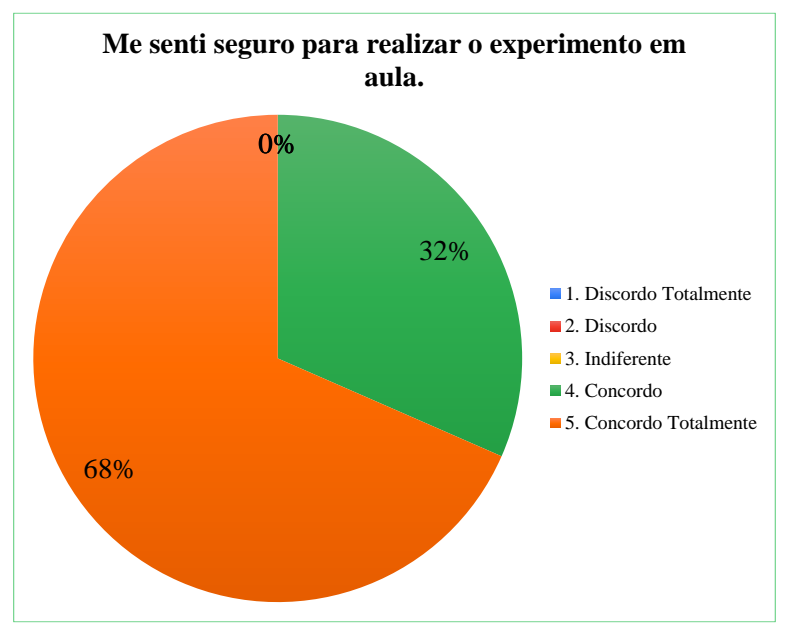

(b)

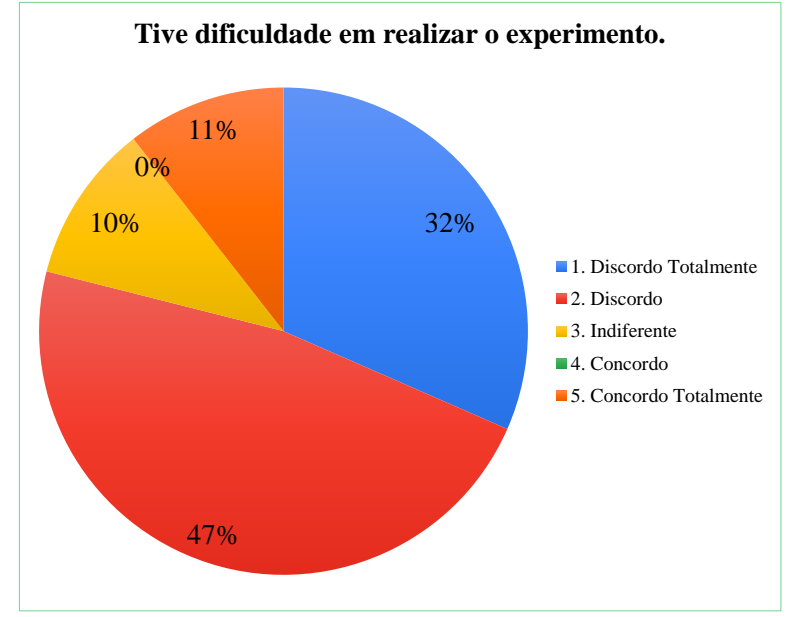

(c)

Na Figura 4 encontram-se os resultados percentuais da percepção geral dos alunos sobre o trabalho desenvolvido durante a atividade, onde é possível observar que $100 \%$ dos estudantes responderam que a atividade trouxe novos aprendizados (Figura 4 a), estimulou a participação na aula em que sua equipe era responsável pelo conteúdo apresentado (Figura 4 b) e ajudou a desenvolver sua capacidade de organização e planejamento (Figura 4 f). Foi unânime também a opinião que os colegas da equipe estavam disponíveis e foram dedicados em atingir as metas estabelecidas para o trabalho (Figura $4 \mathrm{~g}$ ) e que ficaram satisfeitos com a relação que tiveram com seus colegas de equipe e turma (Figura $4 \mathrm{~h}$ ).

Com relação à percepção se a atividade estimulou sua participação nas aulas das outras equipes (Figura $4 \mathrm{c}$ ), se contribuiu com sua capacidade de resolver problemas (Figura $4 \mathrm{~d}$ ) e se melhorou sua capacidade para tomar decisões e trabalhar com o imprevisto e incerteza (Figura 4 e), respectivamente $90 \%, 84 \%$ e $84 \%$ dos alunos disseram concordar ou concordar totalmente.

Todos os estudantes entrevistados responderam que a atividade foi interessante (Figura 4 i) e $95 \%$ deles concordam que mais aulas de laboratório deveriam ser realizadas utilizando essa estratégia, nesta e em outras disciplinas, ou seja, o grau de aceitação foi alto, corroborando a percepção pessoal da professora a respeito do engajamento dos alunos. 
Figura 4 - Resultados percentuais da percepção dos estudantes sobre o material disponibilizado previamente para a preparação da aula.

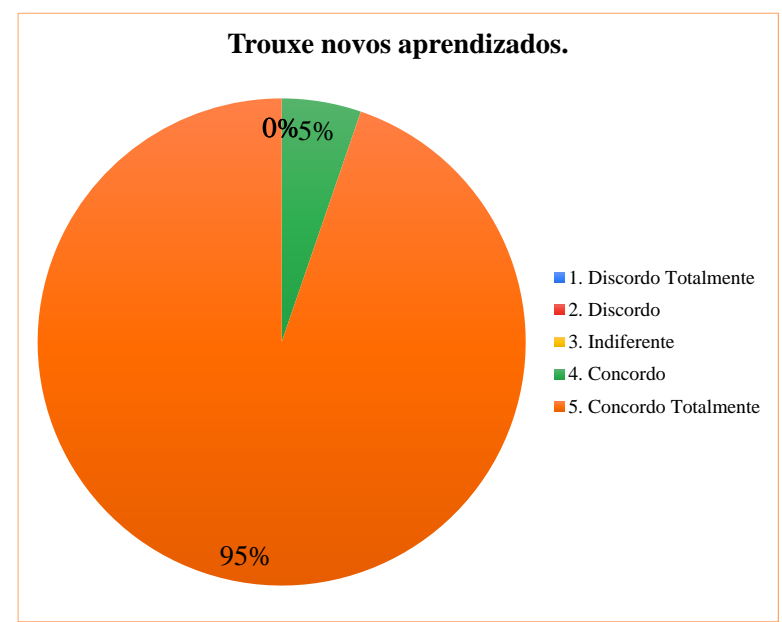

(a)

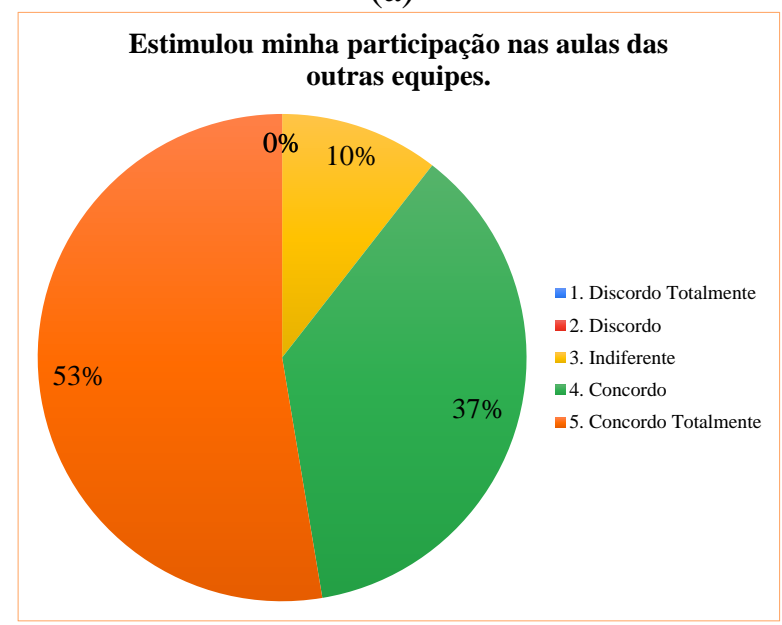

(c)

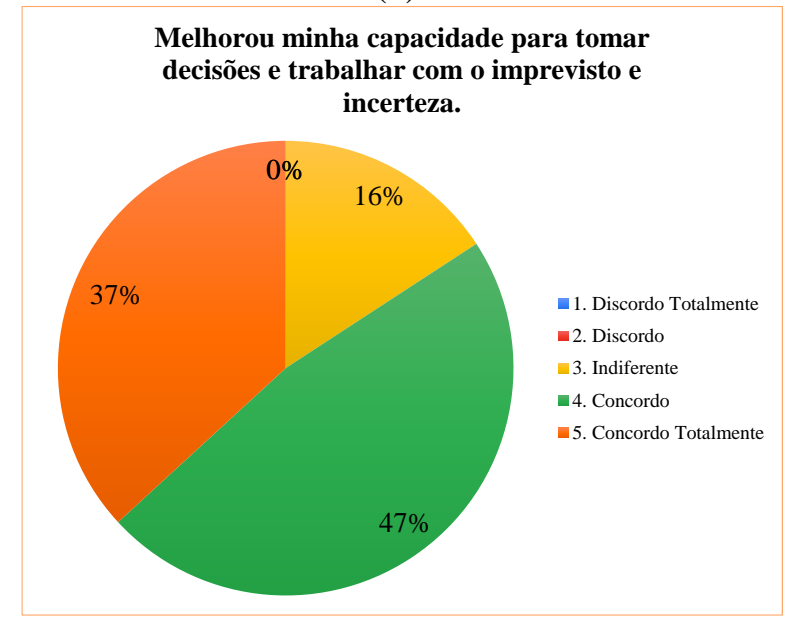

(e)

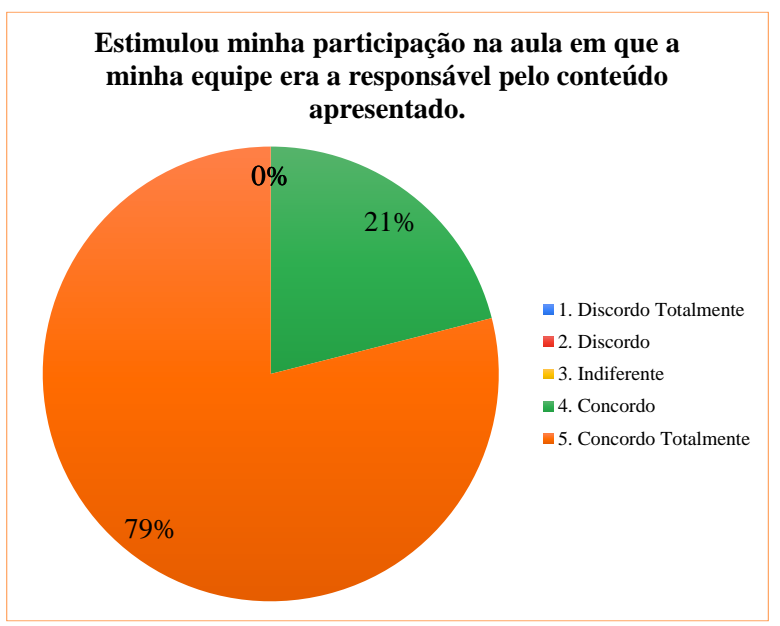

(b)

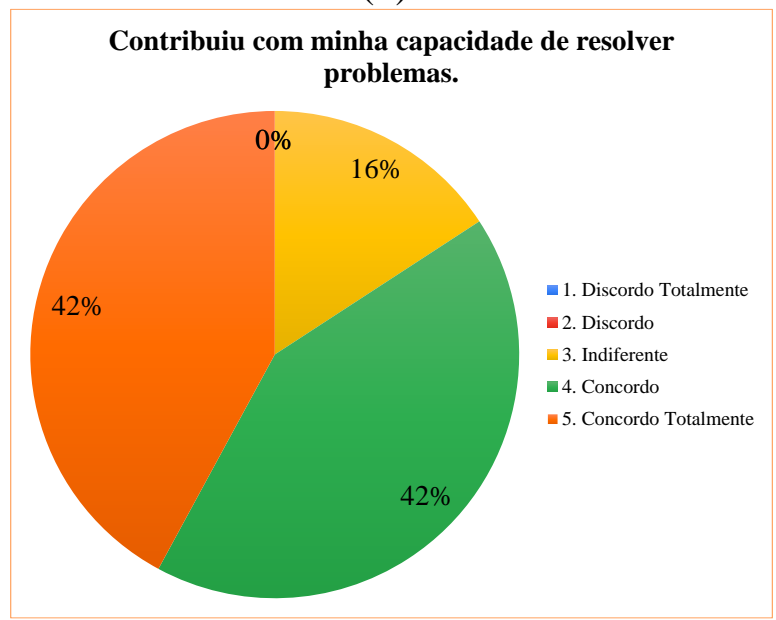

(d)

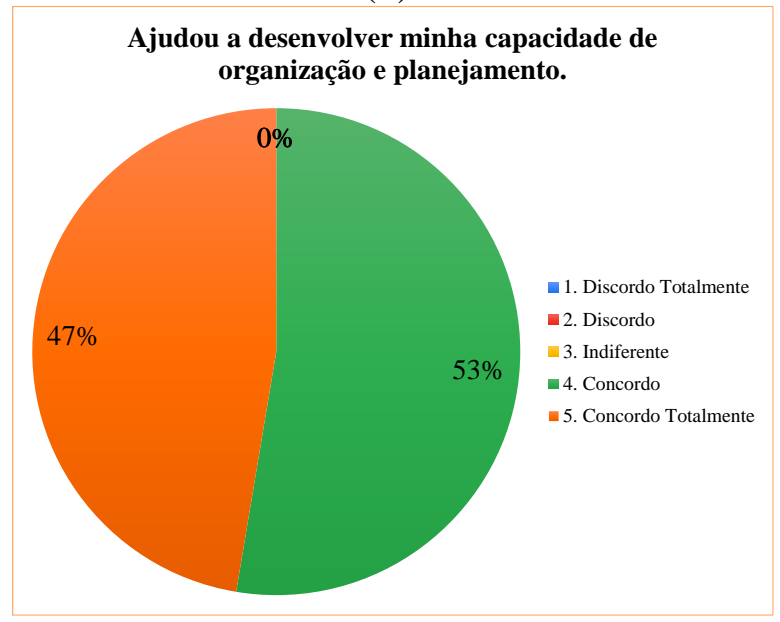

(f) 


\section{O COBENGE C. COBENCE 2020 de Educação em Engenharia de Educação em Engenharia da ABENGE}

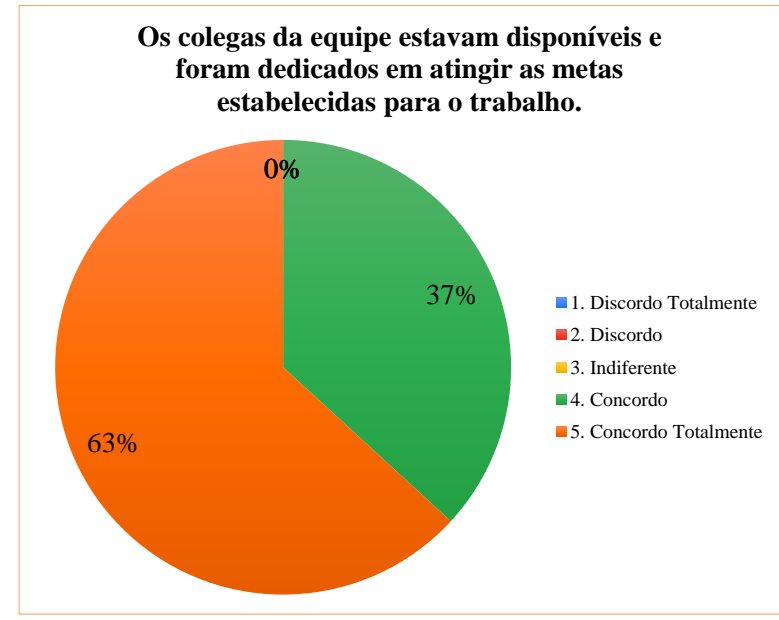

(g)

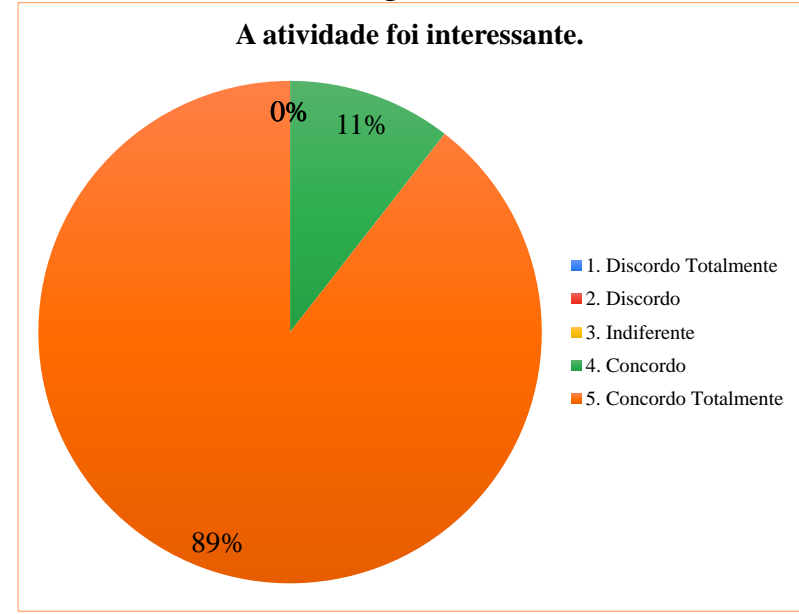

(i)

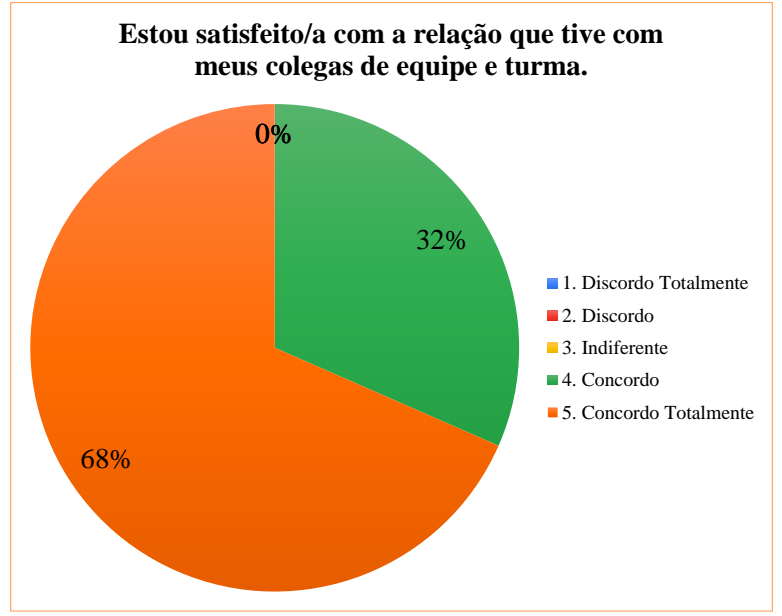

(h)

Mais aulas de laboratório deveriam ser realizadas utilizando essa estratégia, nesta e em outras disciplinas.

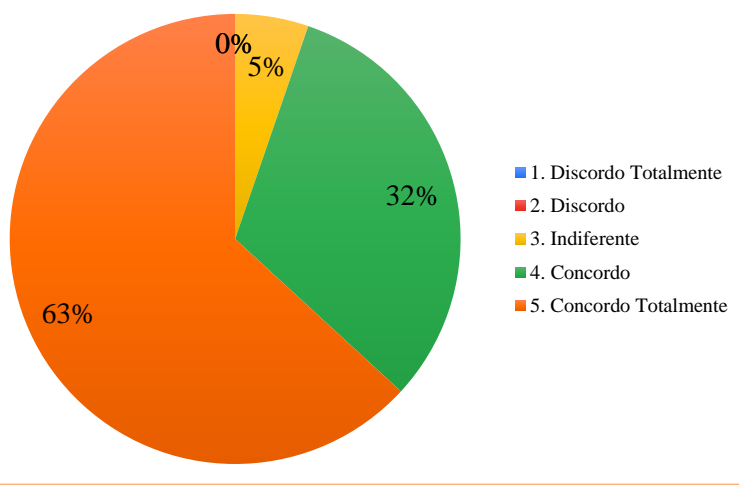

(j)

Quando questionados sobre quais aspectos da atividade foram mais úteis ou valiosos, alguns alunos responderam:

"Interação com a turma e com os materiais";

"A oportunidade de fazer algo sozinho e desenvolver essa habilidade de "se virar"";

"Com os alunos dando aula, isso quebra a barreira um pouco de aluno X professor. Ver um aluno ensinando o experimento, traz uma dinâmica interessante diferente das aulas normais";

"Poder aprender com a prática";

"A proximidade entre os alunos faz com que a aula fique mais dinâmica, com linguagem e pensamentos usuais para o melhor conhecimento dos alunos, já que a aula era feita por eles";

"Ajudou a encontrar informações na norma, melhora o aprendizado pois o aluno acaba procurando mais e se interessando mais sobre o assunto para apresentar uma boa aula para os colegas".

As sugestões de melhoria da atividade foram:

"Achei adequada";

"Creio que permitir que os alunos que estão vendo a aula poderem avaliar os alunos ministrando a aula pode ser uma melhora para ter uma avaliação mais balanceada pela professora";

"Quando meu grupo fez, tivemos alguns problemas na hora de mostrar experimento, e acabamos nos atrapalhando mais ainda com medo de abaixar muito a nota. No nosso caso, a 
professora ajudou bastante na hora, e mesmo assim não tirou tanto ponto, acho que se a gente soubesse que os erros não prejudicariam tanto a nota, não teríamos ficado tão nervosos na hora. Creio que se os alunos forem informados que a avaliação seria em cima do conteúdo da apresentação e não na execução do experimento em si, isso ajudaria na realização da aula";

"Não sei, esses dias estava pensando que deveria ter essas labs para instalações elétricas e hidráulicas";

"Uma ajuda mais próxima da professora no planejamento da aula".

De maneira geral, notou-se o engajamento da maioria dos alunos no processo. As apresentações foram bem-feitas, com conteúdos adequados, material digital (apresentações em ppt) de boa qualidade gráfica e os alunos conduziam os experimentos sob sua responsabilidade com propriedade. Percebeu-se uma maior participação dos outros alunos quando chamados para auxiliar nos ensaios, parecendo que estavam mais à vontade por serem os colegas que estavam à frente da aula. Alguns alunos relataram pessoalmente que acharam a atividade interessante $\mathrm{e}$ gostaram de realizá-la.

\section{CONSIDERAÇÕES FINAIS}

A implantação da ferramenta TBL nas aulas de laboratório de Materiais de Construção Civil foi realizada com sucesso, uma vez que se percebeu o empenho e entusiasmo dos alunos responsáveis pelas aulas e a maior participação dos colegas durante as aulas, o que já não acontecia com tanta frequência nas aulas realizadas pelo método tradicional.

Permitir que o estudante participe de forma ativa, até mesmo conduzindo experimentos sob a supervisão do professor, desenvolve o senso de responsabilidade que é uma atitude desejável dos profissionais de engenharia.

$\mathrm{O}$ fato de os estudantes indicarem que essa estratégia poderia ser utilizada por outras disciplinas que utilizam aulas experimentais, indica uma aceitação positiva. Investir no desenvolvimento da responsabilidade e coparticipação do estudante na construção do currículo, vai ao encontro do desenvolvimento de competências mais globais na formação profissional, alinhando-se às novas DCNs para os cursos de engenharia.

O desafio que se coloca é compartilhar essa experiência com outros professores e implantála de forma mais ampla em outras disciplinas do curso.

\section{Agradecimentos}

Os autores agradecem ao Instituto Mauá de Tecnologia pelo auxílio na realização deste trabalho e aos alunos que responderam à pesquisa.

\section{REFERENCIAS}

BOLLELA, V. R. et al. Aprendizagem baseada em equipes: da teoria à prática. Medicina (Ribeirao Preto. Online), v. 47, n. 3, p. 293, 3 nov. 2014.

BURGESS, A. W.; MCGREGOR, D. M.; MELLIS, C. M. Applying Established Guidelines to Team-Based Learning Programs in Medical Schools. Academic Medicine, v. 89, n. 4, p. 678-688, abr. 2014.

MEC, M. DA E. E C. C. N. DE E. C. DE E. S.-. Resolução CNE/CES nº 2, de 24 de abril de 2019Diretrizes Curriculares Nacionais do Curso de Graduação em Engenharia, 2019. 
MESQUITA, D.; LIMA, R. M.; FLORES, M. A. Developing professional competencies through projects in interaction with companies: A study in Industrial Engineering and Management Master Degree. Fifth International Symposium on Project Approaches in Engineering Education (PAEE'2013): Closing the Gap between University and Industry. Anais...Eindhoven, The Netherlands: 2013

OLIVEIRA, B. L. C. A. DE et al. Team-Based Learning como Forma de Aprendizagem Colaborativa e Sala de Aula Invertida com Centralidade nos Estudantes no Processo EnsinoAprendizagem. Revista Brasileira de Educação Médica, v. 42, n. 4, p. 86-95, dez. 2018.

\title{
THE USE OF TEAM BASED LEARNING IN CIVIL CONSTRUCTION MATERIALS LABORATORY CLASSES IN AN ENGINEERING COURSE
}

\begin{abstract}
Traditional teaching, with a focus on the teacher, has lost strength in recent years due to the learning difficulties and increasing students' lack of motivation. With this, active learning methodologies gained prominence, since the student becomes the protagonist of the process and starts to control his learning pace. Within this scenario, there are several tools, among them: PBL (Problem / Project Based Learning), Inverted Class, Peer Learning, etc. The objective of this work is to use the Team Based Learning (TBL) tool, in the laboratory classes of the discipline Civil Construction Materials at Escola de Engenharia Mauá. The motivation was the growing disinterest of students over the past few years in traditional laboratory classes. For the activity, the students were divided into teams and each one was responsible for one of the experiments of a school term. The previous material for the preparation of the teams was made available on the Moodlerooms platform and the students had the support of the technician for the prior preparation of the experiment that they would carry out with the rest of the class on the day of their presentation. At the end of the process, the teams 'engagement and greater class participation during classes were noted, in addition to the students' positive perception of the process.
\end{abstract}

Keywords: Active learning. Team Based Learning (TBL). Team learning. Didactic laboratory. Civil Construction Materials. 